\title{
Occipital Lobe Infarction due to Acute Hydrocephalus Secondary to Third Ventricle Colloid Cyst in a Child
}

\author{
Nisar A. Wani ${ }^{1}$ Parveen A. Lone ${ }^{2}$ Syed Tariq ${ }^{3}$ \\ ${ }^{1}$ Department of Pediatric Radiology, Government Medical College \\ Srinagar, Jammu and Kashmir, India \\ 2 Department of OMF Surgery, GDC Jammu, Jammu and Kashmir, \\ India \\ ${ }^{3}$ Department of Pediatrics, Government Medical College Srinagar, \\ Jammu and Kashmir, India \\ Indian J Neurosurg 2016;5:101-105.
}

\begin{abstract}
Keywords

- colloid cyst

- hydrocephalus

- third ventricle
\end{abstract}

\begin{abstract}
Address for correspondence Nisar A. Wani, MD, Department of Pediatric Radiology, Government Medical College, Srinagar, Jammu and Kashmir 190008, India (e-mail: ahmad77chinar@gmail.com; nisar.wani@yahoo.com).
\end{abstract}

\section{Introduction}

Colloid cysts comprise 0.5 to $1 \%$ of intracranial tumors that are most commonly diagnosed in third to fifth decade of life. ${ }^{1,2}$ These benign tumors are generally seen in the anterosuperior portion of the third ventricle and are by far the most common of the intraventricular masses here. ${ }^{3,4}$ Colloid cysts are of endodermal (foregut) origin and are lined by pseudostratified, cuboidal, or columnar epithelial cells. Cysts may range in size from 3 to $40 \mathrm{~mm}$ and contain viscous, gelatinous contents with some cellular debris. ${ }^{1-4}$ Colloid cysts of the third ventricle are rare in children. ${ }^{5-8}$ Obstruction of the foramen of Monro by the colloid cyst in the anterosuperior portion of third ventricle may result in noncommunicating hydrocephalus, which may be complicated by central transtentorial herniation manifesting with brainstem compression and posterior cerebral artery

received

April 6, 2015

accepted after revision

December 23, 2015

published online

June 8, 2016 infarction. 5,6,9 We report an 11-year-old boy who presented with acute-onset headache, vomiting, and decreased level of consciousness. Imaging with computed tomography (CT) and magnetic resonance imaging (MRI) demonstrated acute hydrocephalus due to third ventricle colloid cyst with occipital lobe infarction resulting from transtentorial herniation.

\section{Case History}

An 11-year-old boy was admitted to the emergency department with a history of progressively worsening headache and several episodes of vomiting for 1 day followed by generalized tonic-clonic seizures and altered consciousness. There was no history of fever; history was unremarkable. On examination, the child was sick, but afebrile with a Glasgow coma score of 9/15. His pulse was 64
DOI http://dx.doi.org/

10.1055/s-0036-1581989. ISSN 2277-954X. (c) 2016 Neurological Surgeons' Society of India
License terms

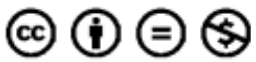


beats per minute and blood pressure was 160/110 mm Hg. Bilateral pupils were dilated and sluggishly reacting to light; no evidence of nuchal rigidity was present. The child was immediately intubated and emergency CT scan of the head was performed. Noncontrast CT showed dilated bilateral lateral ventricles with a well-defined rounded mass obstructing foramen of Monro. The mass showed homogenous attenuation higher than that of cerebrospinal fluid, but slightly lower than that of the brain; the subtle hypodense area was seen in the right thalamus (-Fig. 1). Midbrain appeared elongated anteroposteriorly with effacement of surrounding perimesencephalic and suprasellar cisterns (-Fig. 2). Urgent ventriculoperitoneal (VP) shunt was performed to relieve the hydrocephalus and the patient regained consciousness. MRI of the brain was performed to characterize the mass further. On MRI, the rounded mass in the anterosuperior aspect of third ventricle showed hypointense to isointense signal intensity on T1-weighted (T1 W) sequence as compared with gray matter (-Fig. 3). T2-weighted (T2 W) fluid attenuated inversion recovery images showed hyperintense signal intensity in the mass; mass measured $25 \mathrm{~mm}$ in diameter (-Fig. 4); thin peripheral enhancement of the mass was seen on contrast injection. Diffusion-weighted imaging showed hyperintense signal in the right occipital lobe; smaller foci of hyperintense signal were seen in the left occipital lobe and in right thalamic region (-Fig. 5). Corresponding areas appeared dark on apparent diffusion

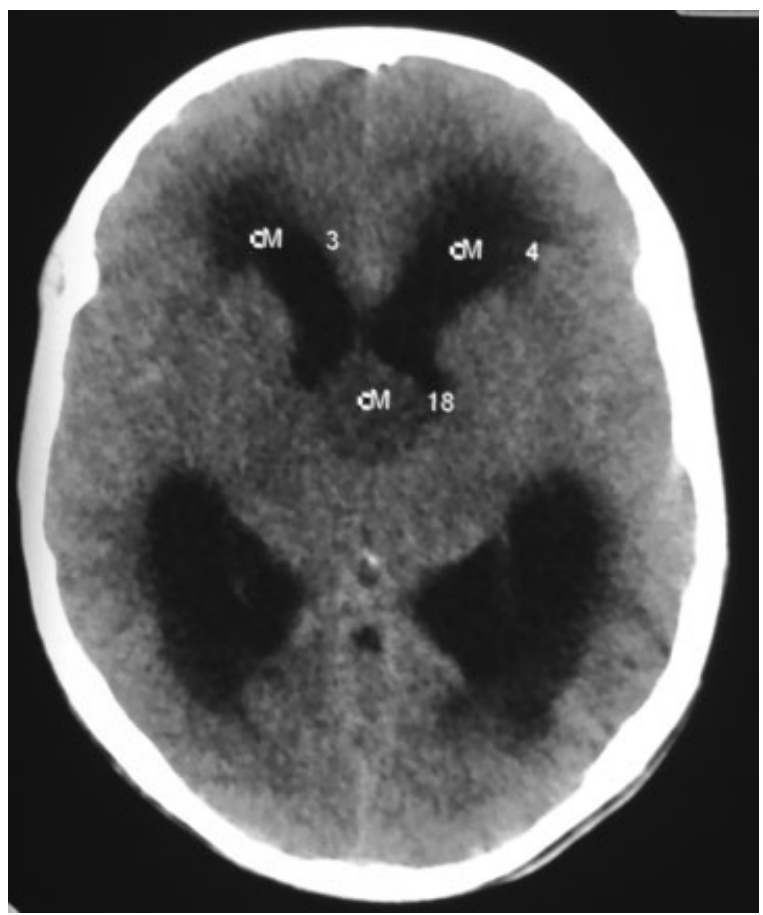

Fig. 1 Noncontrast axial CT image through the lateral ventricles showing dilated lateral ventricles of both the sides with a well-defined rounded mass obstructing foramen of Monro. The mass shows homogenous attenuation higher than CSF and slightly lower than brain. The subtle hypodense area is seen in the right thalamus. CSF, cerebrospinal fluid; CT, computed tomography.

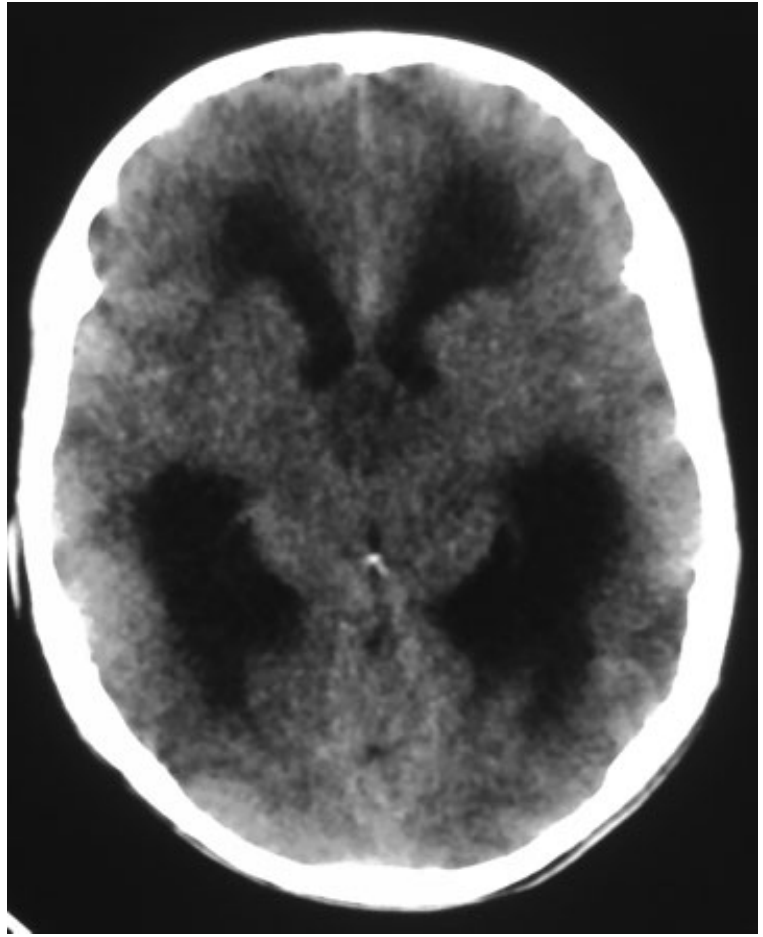

Fig. 2 Noncontrast axial CT image through midbrain showing effaced basal cisterns around midbrain, which appears elongated anteroposteriorly and compressed laterally. CT, computed tomography.



Fig. 3 T1-weighted axial MRI following ventriculoperitoneal shunt showing a rounded mass in the anterior third ventricle with normal right and slightly dilated left lateral ventricle. The mass shows homogenous isointense signal intensity as compared with gray matter. MRI, magnetic resonance imaging. 


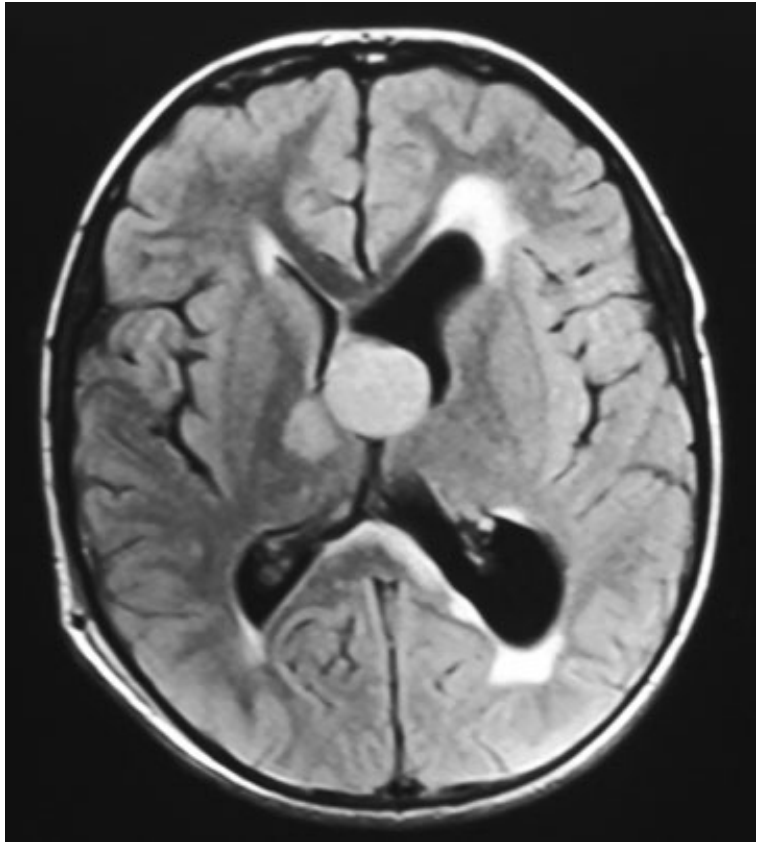

Fig. 4 T2-weighted fluid attenuated inversion recovery axial image shows homogenous hyperintense signal intensity mass in the anterior aspect of the third ventricle close to the foramen of Monro. The hyperintense signal intensity, focus is seen in right thalamus and left occipital lobe and adjacent corpus callosum.



Fig. 5 Diffusion-weighted image showing hyperintense signal intensity in the medial aspect of the right occipital lobe; smaller hyperintense signal areas are seen in right thalamus and left occipital lobe. Artifact related to shunt is seen more peripherally in the right occipital lobe. coefficient maps confirming restricted diffusion due to acute infarction. Basilar and posterior cerebral arteries were normal on MR angiography. Two days after VP shunt placement, patient was conscious with a Glasgow coma score of 15/15. Pulse and blood pressure were normal. Pupils were normal in size and reacting to light. Cranial nerves were normal; no motor or sensory deficit could be elicited. Parents of the child refused surgery and he was discharged with VP shunt in place.

\section{Discussion}

Colloid cysts of the brain are rarely seen in children and only approximately 100 cases have been reported in English literature till date (-Table $\mathbf{1}$ ). ${ }^{4}$ Mathiesen et al reported 37 cases of colloid cyst, 5 of which were found to occur in children. ${ }^{1}$ Alnaghmoosh and Alkhani reported 7 cases of colloid cyst in children in a series of 43 cases. $^{7}$ Desai et al found 14 cases in the pediatric age group in a series of 105 cases of colloid cyst. ${ }^{2}$ Children with colloid cyst are usually 5 to 18 years of age, though colloid cyst has been reported in a 2-month-old infant. ${ }^{3}$ Most of the series describing colloid cyst in pediatric patients report male predominance. ${ }^{4,10-13}$ The cyst may range in size from 3 to $40 \mathrm{~mm}$; giant cysts above $30 \mathrm{~mm}$ are uncommon. ${ }^{11}$ The rate of cyst growth is uncertain and whether all the cysts eventually manifest with symptoms is unclear., ${ }^{3,4}$ Macdonald et al reported that younger patients with colloid cyst are more likely to become symptomatic.

Colloid cyst in pediatric patients may manifest with headache and vomiting with papilledema. Other reported presentations include rapid deterioration of sensorium and sudden death. ${ }^{3-6,13-15}$ These clinical manifestations primarily result from raised intracranial pressure. ${ }^{3,4,15}$ Classically episodic, positional paroxysmal headache is described to result from the ball valve like mechanism obstructing cerebrospinal fluid at the foramen of Monro. ${ }^{1,3,15}$ Rapid development of hydrocephalus may result in acute neurological deterioration or sudden death. ${ }^{3,4,15}$ Sudden death has been proposed to result from transtentorial herniation with brainstem compression compromising cardiac and respiratory centers. Compression of hypothalamic cardiovascular regulatory centers has been postulated to be the cause of death in the absence of herniation. ${ }^{6,7,9}$ Bilateral supratentorial intracranial expansive process like dilated and obstructed lateral ventricles in acute noncommunicating hydrocephalus may precipitate bilateral (central) transtentorial herniation. 3,4,6,7,9 Clinically, first evidence of central herniation is change in alertness followed by respiratory, ocular, and motor signs. ${ }^{9}$ Imaging with CT and MRI may show evidence of herniation as transversely compressed brainstem, which appears elongated on its anteroposterior axis. ${ }^{9}$ The basal cisterns, especially the perimesencephalic and suprasellar cisterns may be obliterated completely; the basilar artery and pineal gland may show a downward shifting. Infarction in the territories supplied by posterior cerebral, thalamoperforate, and superior cerebellar arteries may result from vascular compression at the tentorial notch. ${ }^{9}$ Radiological findings of 
Table 1 Review of colloid cyst in pediatric age

\begin{tabular}{|c|c|}
\hline Study & Observations \\
\hline Macdonald et al, $1994^{5}$ & $\begin{array}{l}\text { Described three children with colloid cysts and reviewed } 34 \text { previously published cases } \\
\text { of colloid cysts in children. They observed that usual presentation was chronic } \\
\text { headaches and increased intracranial pressure. A CT scan or MRI with intravenous } \\
\text { contrast is necessary to identify them. The growth and postoperative recurrence of } \\
\text { cyst argues for treatment by complete surgical excision in children. }\end{array}$ \\
\hline Maqsood et al, $2006^{6}$ & $\begin{array}{l}\text { Described } 18 \text { cases of colloid cyst in children with male predominance. Headache and } \\
\text { vomiting were the most common symptoms; papilledema was the most common } \\
\text { clinical sign. Preoperative CT showed a hyperdense nonenhancing lesion. They } \\
\text { concluded that early recognition and treatment give excellent results. }\end{array}$ \\
\hline Alnaghmoosh and Alkhani, $2006^{7}$ & $\begin{array}{l}\text { Identified seven pediatric patients of colloid cyst } 6 \text { to } 18 \text { y of age. All presented } \\
\text { clinically with features of increased intracranial pressure. The colloid cyst appeared } \\
\text { hyperdense on CT and hyperintense on T2-weighted MR images. All had complete cyst } \\
\text { resection and good outcome. They concluded that colloid cysts in children are } \\
\text { associated with more aggressive clinical and radiological patterns and recommended } \\
\text { early surgical intervention. }\end{array}$ \\
\hline Kumar et al, $2010^{8}$ & $\begin{array}{l}\text { Described five cases of pediatric colloid cysts. They observed that pediatric colloid } \\
\text { cysts were rarer than their adult counterparts due to their late detection after the } \\
\text { manifestations of raised intracranial pressure, visual or cognitive dysfunction, or drop } \\
\text { attacks occurred. The radiological appearance varied depending upon the amount of } \\
\text { mucoid content, cholesterol, proteins, and water content. They suggested that fast } \\
\text { development of clinical manifestations in children was related to rapid enlargement of } \\
\text { cyst due to higher water content within them. They concluded that transcallosal } \\
\text { approach was the "gold standard" of surgery that usually ensured gratifying and } \\
\text { lasting results. }\end{array}$ \\
\hline Kapu et al, $2012^{3}$ & $\begin{array}{l}\text { Described colloid cysts in five children. They noticed the female predominance and } \\
\text { features of raised ICT in the patients. CT showed a hyperdense lesion in the third } \\
\text { ventricle. They maintained that total excision of the lesion was a permanent cure with } \\
\text { minimum morbidity. They concluded that limited anterior callosotomy did not result in } \\
\text { disconnection syndromes or behavioral disturbance. }\end{array}$ \\
\hline Goyal et al, $2014^{4}$ & $\begin{array}{l}\text { Reported a series of eight cases. The authors suggested surgical intervention, even in } \\
\text { incidentally detected colloid cysts. Endoscopic excision was reported to be safe and } \\
\text { effective minimally invasive approach for this cyst. They recommended placement of } \\
\text { external ventricular drain for draining intraventricular blood. }\end{array}$ \\
\hline Kim et al, $2006^{10}$ & $\begin{array}{l}\text { Reported coexistence of a colloid cyst and the neuroglial heterotopias in a 3-year-old } \\
\text { boy. }\end{array}$ \\
\hline Kasliwal et al, $2007^{11}$ & Reported a giant pediatric colloid cyst. \\
\hline Farooq et al, $2008^{15}$ & $\begin{array}{l}\text { Reported a case of hemorrhagic colloid cyst in a 9-year-old girl who presented with } \\
\text { headaches, nausea, and had a sudden deterioration of her mental status. The patient } \\
\text { had an excellent outcome after surgery. }\end{array}$ \\
\hline Goldberg et al, $2011^{13}$ & $\begin{array}{l}\text { Reported acute-onset, brief, repetitive episodes of loss of consciousness in a 10-year- } \\
\text { old girl due to colloid cyst of the third ventricle confirmed by CT and MRI. }\end{array}$ \\
\hline Ma C et al, $2012^{14}$ & Described a case of colloid cysts in the bilateral ventricles. \\
\hline Morris and Santoreneos, $2012^{12}$ & $\begin{array}{l}\text { Reported an 11-year-old boy with memory deficits due to colloid cyst in the region of } \\
\text { the velum interpositum, in the roof of the third ventricle. This lesion was excised } \\
\text { successfully via a transcallosal interfornical approach. }\end{array}$ \\
\hline
\end{tabular}

Abbreviations: $\mathrm{CT}$, computed tomography; ICT, intracranial tension; MRI, magnetic resonance imaging.

elongated brainstem, effaced basal cisterns, and right thalamic and bilateral occipital lobe infarction in our patient who presented with altered mental state were compatible with central transtentorial herniation.

Imaging plays an important role in the diagnosis of colloid cysts which are seen as rounded, well-defined masses in the superior third ventricle with minimal or no wall enhancement. ${ }^{3,4,6,7}$ On CT most of the colloid cysts are of hyperdense, though these may be of hypodense or isodense attenuation compared with brain parenchyma.
Signal intensity on $\mathrm{T} 1 \mathrm{~W}$ and $\mathrm{T} 2 \mathrm{~W}$ MRI is variable with the typical picture being a hyperintense signal on $\mathrm{T} 1 \mathrm{~W}$ and hypointense signal on $\mathrm{T} 2 \mathrm{~W}$ images. ${ }^{3,4,7}$ Sometimes $\mathrm{T} 1 \mathrm{~W}$ hypointense and $\mathrm{T} 2 \mathrm{~W}$ hyperintense signal is present, which may correlate with less of viscous contents and more of water within the cyst. ${ }^{4,7,8}$ Risk factors that increase the likelihood of symptoms of obstruction in colloid cyst include younger age, enlarged ventricles, large cyst size, and hyperintense signal intensity cyst contents on $\mathrm{T} 2 \mathrm{~W}$ MRI. ${ }^{3-6,8}$ Children usually tend to have a higher proportion 
of T2 W hyperintense cysts which tend to have a higher risk of future expansion. ${ }^{4,7,8}$ The features in our case did portend higher risk of symptoms.

Rapidly enlarging and symptomatic colloid cysts need neurosurgical intervention. ${ }^{8,9}$ Colloid cysts in children are reported to be more aggressive, hence, early surgical intervention is suggested even in incidentally detected cysts. ${ }^{4,8}$ Temporary or permanent VP shunt may be necessary to manage hydrocephalus. ${ }^{1-4}$ Endoscopic or stereotactic aspiration of the cyst contents may be performed; however, cyst tends to recur after aspiration. 1,3,5,6 Hyperdense attenuation of the cyst contents on $\mathrm{CT}$ and hyperintense signal on T1 W MRI predicts difficulty during aspiration., 3 Open excision (transcortical/transcallosal) or endoscopic excision (transcallosal-transventricular) may be employed for surgical resection of the cyst. ${ }^{3,4,6-8}$ The external ventricular drain is recommended to be kept in place after surgery. ${ }^{4}$

\section{Conflict of Interest}

None.

\section{References}

1 Mathiesen T, Grane P, Lindgren L, Lindquist C. Third ventricle colloid cysts: a consecutive 12-year series. J Neurosurg 1997; 86(1):5-12

2 Desai KI, Nadkarni TD, Muzumdar DP, Goel AH. Surgical management of colloid cyst of the third ventricle-a study of 105 cases. Surg Neurol 2002;57(5):295-302, discussion 302-304
3 Kapu R, Symss NP, Pande A, Vasudevan MC, Ramamurthi R. Management of pediatric colloid cysts of anterior third ventricle: A review of five cases. J Pediatr Neurosci 2012;7(2):90-95

4 Goyal N, Sharma BS, Mahapatra AK. Third ventricular colloid cysts in children - a series of eight cases and review of the literature. Turk Neurosurg 2014;24(1):1-7

5 Macdonald RL, Humphreys RP, Rutka JT, Kestle JR. Colloid cysts in children. Pediatr Neurosurg 1994;20(3):169-177

6 Maqsood AA, Devi IB, Mohanty A, Chandramouli BA, Sastry KV. Third ventricular colloid cysts in children. Pediatr Neurosurg 2006;42(3):147-150

7 Alnaghmoosh N, Alkhani A. Colloid cysts in children, a clinical and radiological study. Childs Nerv Syst 2006;22(5):514-516

8 Kumar V, Behari S, Kumar Singh R, Jain M, Jaiswal AK, Jain VK. Pediatric colloid cysts of the third ventricle: management considerations. Acta Neurochir (Wien) 2010;152(3):451-461

9 Laine FJ, Shedden AI, Dunn MM, Ghatak NR. Acquired intracranial herniations: MR imaging findings. AJR Am J Roentgenol 1995; 165(4):967-973

$10 \mathrm{Kim}$ YH, Wang KC, Lee YK, Chi JG, Cho BK, Kim SK. Coexistence of colloid cyst and neuroglial heterotopia. Childs Nerv Syst 2006; 22(10):1360-1363

11 Kasliwal MK, Kiran S, Agrawal D, Sharma BS. Giant colloid cyst in a child. Pediatr Neurosurg 2007;43(5):442-443

12 Morris TC, Santoreneos S. Colloid cyst of velum interpositum: a rare finding. J Neurosurg Pediatr 2012;9(2):206-208

13 Goldberg EM, Schwartz ES, Younkin D, Myers SR. Atypical syncope in a child due to a colloid cyst of the third ventricle. Pediatr Neurol 2011;45(5):331-334

14 Ma C, He X, Li Q Jiang F, Ma J. A rare case of pediatric colloid cysts in bilateral ventricles. Pediatr Neurosurg 2012;48(6): 371-373

15 Farooq MU, Bhatt A, Chang HT. Hemorrhagic colloid cyst in a 9-year-old girl. Pediatr Neurol 2008;38(6):443-444 